\title{
Increased sensitivity to cis-diamminedichloroplatinum induced apoptosis with mitochondrial DNA depletion
}

\author{
Bertrand C. Liang ${ }^{1,2,3,4}$ and Elizabeth Ullyatt ${ }^{2}$ \\ ${ }^{1}$ Department of Medicine (Medical Oncology), University of Colorado Health \\ Sciences Center, Denver, Colorado, USA \\ ${ }^{2}$ Department of Neurology, University of Colorado Health Sciences Center, \\ Denver, Colorado, USA \\ ${ }^{3}$ Department of Pathology, University of Colorado Health Sciences Center, \\ Denver, Colorado, USA \\ ${ }^{4}$ corresponding author: University of Vermont College of Medicine, Human \\ Medical Genetics Unit, Medical Alumni Building A208, Burlington, VT 05405 \\ tel: (802) 656-3487; fax: (802) 656-5368
}

Received: 20.10.97; revised: 2.1.98; accepted 2.4.98

Edited by J.C. Reed

\begin{abstract}
Malignant cells harbor mechanisms which allow escape from drug-induced apoptosis, and the drug-resistance phenotype can be significantly associated with resistance to programmed cell death. There is accumulating evidence that mitochondria play a role in the tumorigenic phenotype, including the relative resistance to apoptosis. Whether changes at the mitochondrial level per se, would impact on the relative sensitivity of malignant cells to undergo druginduced apoptosis, is not know. Accordingly, we determined if depleting mitochondrial DNA (mtDNA) would change the susceptibility of U937 cells to undergo apoptosis. With depletion, increases in sensitivity to cis-diamminedichoroplatinum (cisplatin)-induced apoptosis was observed. This sensitivity could be reverted to the parental phenotype by transforming the depleted cells with normal platelet mitochondria. MRNA expression of BAX, BCL2, MDR1, MRP, ERCC1 and ERCC2, putatively associated with cisplatin resistance to apoptotic death was unchanged. Inhibition of mitochondrial ATP production by oligomycin did not result in a change in ATP levels, indicating energetics were not playing a role in the observed phenotype changes. All U937 cells (with/without mtDNA) continued to respond to cisplatin by an apoptotic death. MtDNA-encoded molecules may be playing a role in the relative sensitivity of cells to undergo a cisplatin-induced apoptotic death, but may not be required for cells to undergo apoptosis per se.
\end{abstract}

Keywords: tumorigenicity; mitochondria; drug resistance; U937

Abbreviations: $\mathrm{EtBr}$, ethidium bromide; mtDNA, mitochondrial DNA; cisplatin, cis-diamminedichloroplatinum; rho+, parental cells with de novo mitochondria; rho(-), mitochondrial DNA/mitochondria-depleted cells; cybrid, rho(-) cells transformed with normal platelet mitochondria; $L D_{50}$, lethal dose of drug resulting in $50 \%$ death

\section{Introduction}

The resistance of malignant cells to undergo cellular death induced by chemotherapeutic agents is a major problem in the treatment of cancer. While many if not most cytotoxic agents induce apoptosis in malignant cells, tumors harbor mechanisms which allow escape from such cellular death; this can include overexpression of drug resistance genes (e.g. MDR1, MRP), as well as changes in downstream events in the apoptotic pathway (e.g. expression changes of BCL2, BAX) (Hannun, 1997). Recent studies have revealed that the drugresistance phenotype can be significantly associated with resistance to apoptosis, induced either by drugs or by physiologic stimuli (viz. Fas) (Landowski et al, 1997; Friesen et al, 1996). Hence, it has been postulated that as tumors develop mechanisms of drug resistance, they also develop mechanisms which allow resistance to apoptosis in general (Hannun, 1997; Landowski et al, 1997). As a result, understanding the mechanisms which underlie drug-induced apoptosis, and increasing the malignant cell sensitivity to such processes, is an important goal in treating cancer.

Apoptosis has been noted to occur without the requirement of cell nuclei nor DNA fragmentation, and non-nuclear cytoplasmic structures are thought to participate in its control (Jacobson et al, 1994; Schulze-Osthoff et al, 1994). Alterations in mitochondrial structure and function occur early during apoptosis, before nuclear or chromatin structures are affected (Zamzani et al, 1995; Petit et al, 1995; Cossarizza et al, 1995; Castedo et al, 1995; Kroemer et al, 1995), suggesting mitochondria may play a pivotal role in the process. Early findings include reduction in the mitochondrial transmembrane potential $(\Delta \Psi \mathrm{m})$, effected by opening of permeability transition pores; this has been found to be capable of inducing the nuclear changes observed in apoptosis, via release of a pre-apoptotic ('mitochondrial associated') factor (Marchetti et al, 1996a). Recent studies suggest this protein is coded by nuclear genes, and harbored within the mitochondria, since mitochondria from transcriptionally inactive cells both with and without mitochondrial DNA (mtDNA), can induce apoptosis in isolated nuclei (Marchetti et al, 1996b). In distinct contrast, there are also recent reports of non- $\Delta \Psi \mathrm{m}$ dependent apoptosis associated with release of cytochrome $c$ from the mitochondrial intermembrane space (Yang et al, 1997; Kluck et al, 1997). Finally, there are recent studies that indicate, in small chain fatty acid induced apoptosis, that mitochondria play a role in cell cycle arrest and initiation (but not the process) of apoptosis (Heerdt et al, 1997). Whether changes at the mitochondrial level per se would impact on the relative sensitivity of a malignant cell to undergo drug-induced apoptosis, is not know.

As a result, we sought to determine if removing mitochondrial DNA (mtDNA) would change the suscept- 
ibility of U937 lymphoma cells to undergo apoptosis. Specifically, our goal was to determine if manipulations of mtDNA would effect changes in sensitivity to cisdiamminedichloroplatinum (cisplatin)-induced apoptosis. We report here that depletion of mtDNA is associated with increases in sensitivity to cisplatin-induced apoptosis in U937 cells, when compared to parental controls with mtDNA present. Such increased sensitivity could be reverted to the parental phenotype by transforming the mtDNA-depleted cells with normal platelet mitochondria. No changes were noted in the mRNA expression of BAX, BCL2, MDR1, MRP, ERCC1 nor ERCC2, which has been associated with resistance to cisplatin-induced death. Inhibition of mitochondrial ATP production by oligomycin did not result in a change in ATP levels in any of the cells, indicating energetic functions were not playing a role in the observed phenotype. All U937 cells continued to respond to cisplatin by an apoptotic death, regardless of the presence or absence of mtDNA. MtDNA-encoded molecules may therefore be playing a role in the relative sensitivity of cells to undergo a cisplatin-induced apoptotic death, but may not be required for cells to undergo apoptosis per se.

\section{Results}

\section{Creation and characterization of cells}

mtDNA levels and auxotrophic dependence To assess the contribution of mtDNA to the phenotype of relative apoptosis resistance, U937 cells ('rho+') were exposed to long-term to ethidium bromide (EtBr), to deplete mtDNA ('rho(-)'). The characterization of these cells included both determination of uridine and pyruvate auxotrophy, as well as direct measurement of mtDNA levels. The results of these evaluations are seen in Figure 1. After U937 cells were exposed to $\mathrm{EtBr}$ for 30 population doublings, cells were placed into either uridine/pyruvate supplemented or unsupplemented medium. In the supplemented medium, cells continued to grow; however, in the unsupplemented medium, the $\mathrm{EtBr}$ treated cells did not further divide, and underwent progressive loss of cell viability over 6 days. The mechanism of cellular death included chromatin condensation, indicating the cells died an apoptotic death (Richter et al, 1996) (Figure 1a), which we have noted in other rho(-) cell types (Cavalli et al, 1997). Non-treated cells remained viable with removal of these supplements. When cells treated as such were assessed for mtDNA levels, less than $1 \%$ of the hybridization signal was noted when comparing the de novo cells with the $\mathrm{EtBr}$ treated ones (Figure 1b, Table 1). Based on the auxotrophic dependence of these cells to uridine/pyruvate, and that little mtDNA was noted by dot blot hybridization, these cells were considered rho(-) (viz. mtDNA depleted) when used in subsequent experiments.

Cybrids To determine the relative contribution of the mtDNA to changes in phenotype of the rho $(-)$ cells, cybrids were constructed from these rho(-) cells using normal platelet transformation (Cavalli et al, 1997). Platelet mediated transformation was used, rather than enucleation and fusion of de novo rho+ U937 cells, since we wished to avoid transferring other malignant cytoplasmic components of the tumor cells into the rho $(-)$ cells, which could potentially influence the drug-induced apoptosis resistant phenotype. Cybrids had similar mtDNA levels to rho+ cells, and were not auxotrophically dependent (Figure 1b, Table

A.
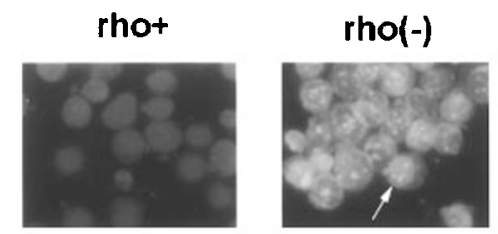

cybrid

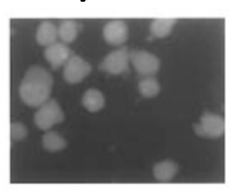

B.

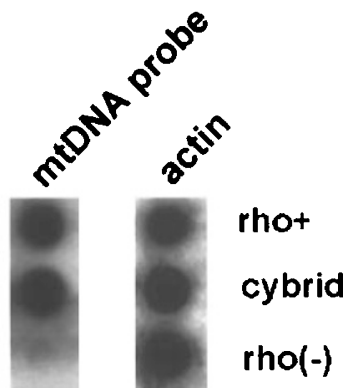

Figure 1 Auxotrophic dependence and mitochondrial DNA levels in U937 cells. (A) Acridine orange/ethidium bromide staining of U937 rho(-) cells after withdrawal of uridine and pyruvate. Mitochondrial DNA-less U937 cells (rho $(-))$ were created by exposing U937 cells (rho+) to ethidium bromide. Cells were isolated after withdrawal of uridine and pyruvate supplements, and stained with acridine orange and ethidium bromide to determine the viability and/or type of cell death. Cells without an active respiratory chain are auxotrophic to uridine and pyruvate, and such auxotrophy is a senstive test for mitochondrial DNA depletion. Note areas of chromatin condensation (arrows) in the rho $(-)$ cells indicative of apoptosis. rho+ and cybrid cells remained viable in uridine and pyruvate-free medium revealing no chromatin condensation, indicating lack of auxotrophic dependence. (B) DNA dot blot. $1 \mu \mathrm{g}$ of DNA from rho+, rho(-) and cybrid cells was dot blotted onto a nylon membrane, and hybridized with mitochondrial DNA sequence. Note increased hybridization of the rho+ when compared to rho(-) cells; less than $1 \%$ of the mitochondrial hybridization signal was noted comparing rho $(-)$ to rho+ cells, after being normalized to a $\beta$-actin control. Cybrids showed similar levels of mitochondrial DNA sequence to the rho+ control. Correlate with Table 1

Table 1 Characteristics of U937 cells

\begin{tabular}{lccc}
\hline & rho+ $^{\mathbf{a}}$ & rho(-) & Cybrid \\
\hline LD $_{50}{ }^{\mathrm{b}}$ & $63 \pm 3.1 \mu \mathrm{M}$ & $35 \pm 0.28 \mu \mathrm{M}$ & $58 \pm 4.1 \mu \mathrm{M}$ \\
mtDNA level $^{\mathrm{c}}$ & 6 & $<1$ & 6.3 \\
BAX $^{\mathrm{d}}$ & $79 \pm 9$ & $77 \pm 12$ & $66 \pm 14$ \\
BCL2 $^{\mathrm{d}}$ & $138 \pm 6$ & $112 \pm 24$ & $126 \pm 20$ \\
MDR1 $^{\mathrm{d}}$ & $52 \pm 12$ & $38 \pm 8$ & $47 \pm 6$ \\
MRP $^{\mathrm{d}}$ & $33 \pm 17$ & $27 \pm 12$ & $38 \pm 2$ \\
ERCC1 $^{\mathrm{d}}$ & $89 \pm 12$ & $92 \pm 13$ & $96 \pm 8$ \\
ERCC2 $^{\mathrm{d}}$ & $56 \pm 6$ & $52 \pm 6$ & $68 \pm 8$ \\
\hline
\end{tabular}

a rho+=parental U937 cells; rho $(-)=$ mtDNA-less cells; cybrid=plateletmediated mitochondrial transformation of rho $(-)$ cells. ${ }^{b} L_{50}=$ lethal dose of $50 \%$ of cells treated with cisplatin for $1 \mathrm{~h}$. ${ }^{c}$ Normalized to $\beta$ actin control and expressed as fold-difference (increase) compared to peripheral blood lymphocytes. ${ }^{d}$ Reverse northern analysis; densitometry levels expressed in relative units, normalized to a $\beta$-actin control; $n=3$ 
1). To confirm the cybrids truly represented a parent nuclear background with mitochondria from the platelet donor, two experiments were performed. A polymorphic marker (D10S591) was used which was found to be different from the U937 cells and the donor nuclear DNA, with PCR showing that the cybrids and rho+ cells were similar, and distinctly different from the donor (Figure 2). For mitochondrial identity, we took advantage of a polymorphism in the noncoding region of mtDNA present in the donor but not in the U937 cells; at position 44, there is a guanine which replaces a cytosine, which creates a Taql site (Figure 2). The cybrids show digestion of the PCR product from position 1546 to 705 on the Southern analysis of the partial Taql digest, not present in the rho+ cells. Hence, cybrids represented parental nuclear background with donor mitochondria.

\section{Analysis of drug resistance and apoptosis genes}

To characterize the U937 lymphoma cells [rho+, rho(-), cybrid] assessment of the mRNA levels of the apoptosis genes BAX and BCL2, as well as drug resistance genes MDR1 and MRP were performed. In addition, changes in mRNA levels of ERCC1 and ERCC2 were determined, since these genes may be involved in apoptosis resistance to cisplatin in other tumor types $(18,19)$. Table 1 shows the results of the reverse northern evaluation, expressed as densitometric measurement normalized to a $\beta$-actin hybridi-

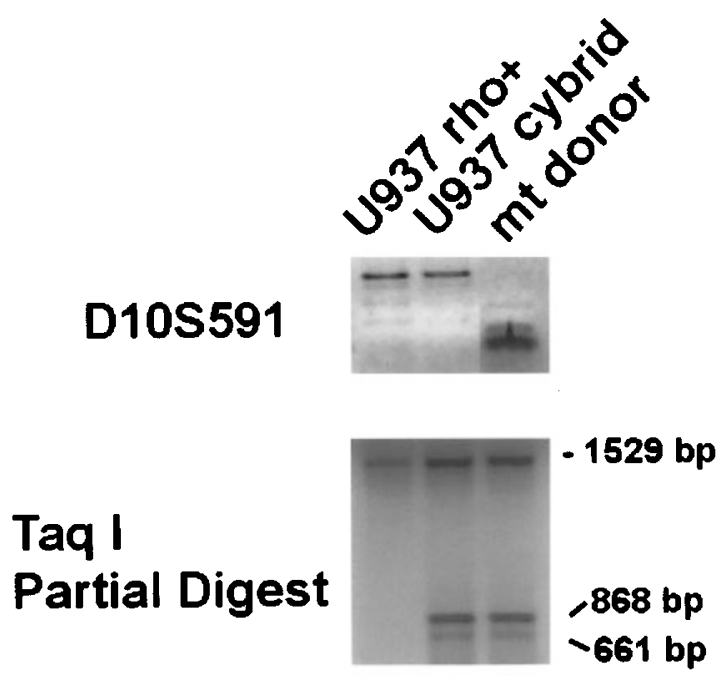

Figure 2 Nuclear and mitochondrial identity of cybrids. ${ }^{32} \mathrm{P}$-labelled polymorphic marker D10S591 was used to distinguish the mitochondrial donor nuclear DNA from the tumor DNA by PCR. Note similarity of the rho+ pattern with the cybrid, while the donor is distinctly different, indicating the nuclear background of the cybrids is from the rho+ cells. Southern analysis of a partial Taql digest of PCR product corresponding to positions 15746 to 705 , hybridized with a mitochondrial probe of the same sequence. The mitochondrial donor has a polymorphism at position 44 in the mitochondrial genome, resulting in the creation of a Taql site, with fragments of 868 and 661 bases after digestion. The rho+ cells do not harbor this polymorphism, and are not digested by Taql. In contrast, the cybrids show digestion of the PCR product, similar to the donor, indicating the source of mitochondria is from the donor zation. Although there were relative differences in the expression of the different genes evaluated, no changes in mRNA expression were noted of the apoptosis genes BAX and BCL2, which have been correlated to changes in sensitivity to drug-induced apoptosis (Hannun, 1997). Similarly, the drug-resistance genes MDR1 and MRP did not show significant differences in expression when comparing the rho+, rho $(-)$ and cybrid cells. The DNA repair genes ERCC1 and ERCC2, which have been reported to have mRNA overexpression in ovarian carcinoma tissues of cisplatin resistant patients, were not found to be different in the rho+, rho $(-)$ or cybrid cell populations. Thus, depletion of the mtDNA from the rho+ cells, and creation of cybrids, did not affect mRNA expression of the apoptosis-related, multidrugresistant, or nucleotide-excision repair genes.

\section{Drug Sensitivity of U937 rho+, rho(-) and cybrid cells}

The U937 cells were then evaluated for response to cisplatin. Figure 3 shows the results of a cisplatin dose response $(1 \mathrm{~h}$ exposure), of the rho+, rho(-), and cybrid U937 cells. rho(-) cells were substantially more sensitive to the apoptotic effects of cisplatin exposure than were the rho+ cells from which they were derived. Indeed, these rho $(-)$ cells were about twice as sensitive as the rho+ cells to the effects of cisplatin, with an $\mathrm{LD}_{50}$ of $35 \mu \mathrm{M}$ (Table 1). Indeed, the $\mathrm{LD}_{50}$ of the rho+ U937 cells was $63 \mu \mathrm{M}$ and doses of cisplatin above $10 \mu \mathrm{M}$ were significantly different between the rho+ and rho $(-)$ cells $(P<0.01$, Student $t$-test).

Cybrid cells derived from the rho $(-)$ cells were then evaluated for response to cisplatin. The cybrids exhibited a similar response to cisplatin exposure as the rho+ cells.

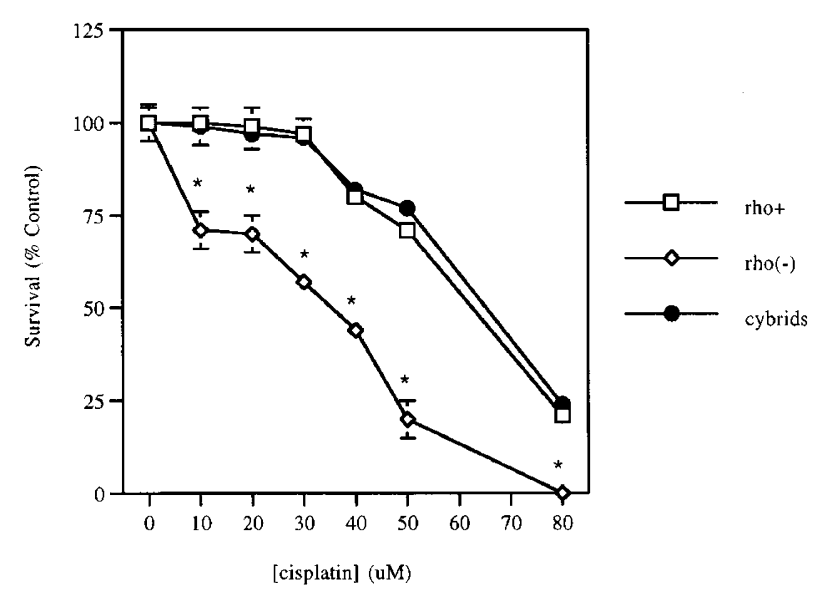

Figure 3 Sensitivity of U937 cells to cisplatin-induced apoptosis. rho+, rho $(-)$ and cybrid cells were exposed to cisplatin at progressively higher concentrations. rho $(-)$ cells were much more sensitive to the effects of cisplatin than the parental cells, with an $\mathrm{LD}_{50}$ of $35 \mu \mathrm{M}$ compared with the rho+ cells ( $\mathrm{LD}_{50} 63 \mu \mathrm{M}, P<0.01$, Student $t$-test). When mitochondria were returned to the rho $(-)$ cells, the dose response returned to that of the parental rho+ cells ( $\mathrm{LD}_{50} 58 \mu \mathrm{M}, P>0.10$, Student $t$-test, compared to the rho+ cells). Positive error is shown for the rho+ cells, negative error for the cybrids, and both errors for the rho $(-)$ cells. * Indicate significant differences of the rho+ cells vs the rho $(-)$ cells $(P<0.01$, Student $t$-test $)$ 
A.

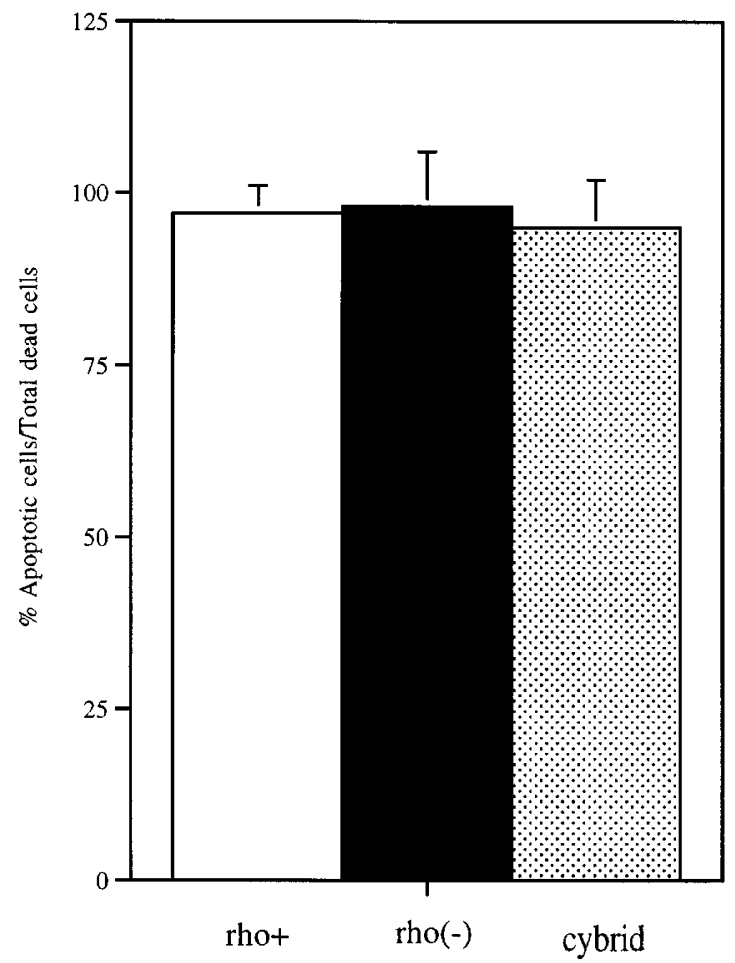

B.

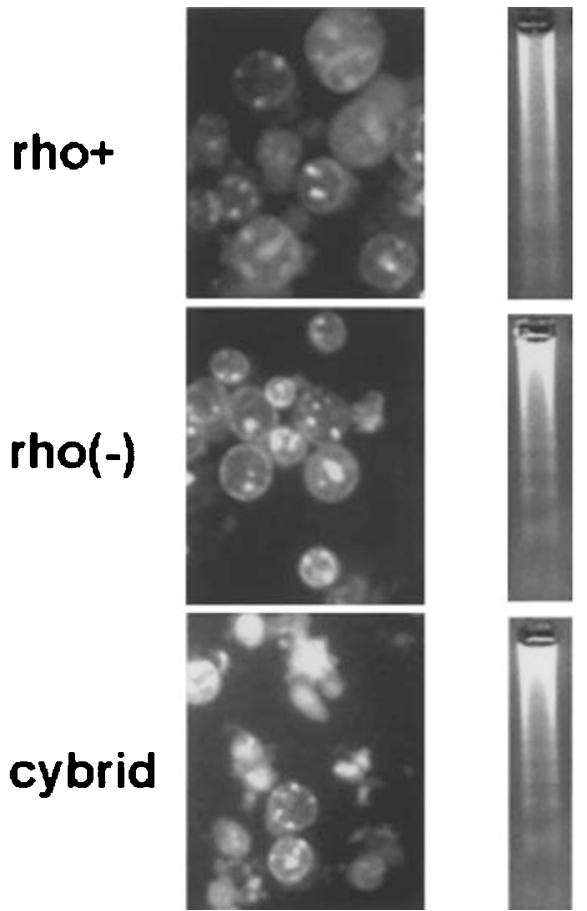

Figure 4 Type of cellular death induced by cisplatin in U937 cells. (A) Percentage of dead cells undergoing apoptosis. rho+, rho(-) and cybrid cells were treated with cisplatin and stained with acridine orange and ethidium bromide to determine type of cell death. Cells showing chromatin condensation were expressed as a percentage of total counted cells. At the $\mathrm{LD}_{50}$, the vast majority of dead cells underwent apoptosis, regardless if mitochondrial DNA was present or absent. There were no significant differences between the rho( -$)$ and cybrids when compared to the rho+ cells as to the percentage of cells which showed apoptotic changes. At least
Indeed, no difference was noted at any dose evaluated between the rho+ U937 cells, and the cybrids constructed from the rho( -$)$ cells and normal platelet mitochondria. The cisplatin $\mathrm{LD}_{50}$ of the cybrids was $58 \mu \mathrm{M}$, which was not different from the rho+ cells $(P>0.10$, Student $t$-test) but significantly different from the U937 rho $(-)$ cells $(P<0.01$, Student $t$-test) (Table 1). Of interest was the finding that the mtDNA levels of the rho+ and cybrid cells were similar, i.e., cybrids achieved similar mtDNA levels as the rho+ cells. This would suggest that there are influences in the rho+ and cybrid tumor cells which allow increased levels of mtDNA to exist compared to normal tissue.

\section{Cisplatin-induced apoptotic death in rho+, rho(-) and cybrid cells}

The mitochondria can be an active participant in cisplatininduced apoptosis (Hannun, 1997), which is either mitochondrial membrane potential dependent (Marchetti et al, 1996a,b) or independent (Yang et al, 1997; Kluck et al, 1997). As the rho( - ) cells were more sensitive to cytotoxic chemotherapy, we assessed whether cell death induced by cisplatin continued to be apoptotic in type or if there had been a change (to necrosis) when compared to the de novo (rho+) cells with mitochondria present. In addition, this would reveal whether mtDNA per se was required for cisplatin-induced apoptosis, or whether the organelle was involved only in events leading up to drug-induced programmed cell death. Cybrids were also assessed for the type of cellular death in response to cisplatin. Figure 4 shows the percentage of dead cells which revealed apoptotic changes; virtually all dead cells evaluated after treatment with the $\mathrm{LD}_{50}$ concentration of cisplatin, whether rho+, rho(-) or cybrid, exhibited signs of apoptosis. No differences were detected between any of the groups (rho+, rho(-), cybrid) with regard to relative percentages of apoptotic (vs. necrotic) cells after cisplatin treatment $(P>0.10$, Student $t$-test). In Figure 4, note chromatin condensation after acridine orange and EtBr staining in the rho+, rho(-) and cybrid cells, and characteristic ladder formation of DNA from the cisplatin treated cells separated in a $1 \%$ agarose gel. These results were noted regardless of the cisplatin concentration utilized. Hence, removal of mtDNA did not prevent an apoptotic death with exposure to cisplatin, suggesting mitochondrially related molecules are not required for the induction of apoptosis (but may be related to events relevant to sensitivity to apoptosis).

\section{Effects of inhibition of ATP production by mitochondria}

To determine whether changes in mitochondrially derived ATP levels were accounting for the increases in sensitivity to cisplatin-induced apoptosis in the rho $(-)$ cells, the rho+, rho( $(-)$, and cybrid cells were treated with oligomycin, to

400 cells were assessed per experiment, repeated thrice. (B) Example of acridine orange and ethidium bromide staining and DNA ladders of treated cells showing apoptotic changes 
inhibit mitochondrial $F_{0} F_{1}$-ATPase. Results are noted in Figure 5. Treatment with oligomycin $(12 \mu \mathrm{M})$ did not alter the ATP levels in U937 rho+ cells. When compared to untreated rho+ cells, no differences were noted in the amount of ATP present in the rho+, rho $(-)$, nor cybrid cells, with oligomycin treatment. This is in accordance to early reports that tumor cells utilize glycolysis for ATP generation in preference to mitochondrially mediated oxidative phosphorylation (Warburg et al, 1926), and our findings that cells continued to die an apoptotic death without mitochondria (previous section), since ATP is required for programmed cell death (Eguchi et al, 1997). As the concentration of oligomycin essentially halts any mitochondrial ATP production (Eguchi et al, 1997), and that no differences were noted of the relative ATP levels, these cells (rho+, rho $(-)$, cybrids) must be utilizing glycolysis for the majority of ATP production. Hence, mitochondrial energy production per se (or lack thereof) is not responsible for the current observations.

\section{Discussion}

Prevention of apoptosis has been implicated in relative resistance of neoplastic cells to cytotoxic agents (Miyashita and Reed, 1993; Lim, 1996; Decaudin et al, 1997). Accumulating evidence has suggested that mtDNA may be involved in resistance to cisplatin-induced apoptosis. The current study directly implicates the mtDNA-encoded molecules as a particularly relevant participant in sensitivity to drug (cisplatin)-induced apoptosis and reveals such molecules can participate in events leading to, but may not be strictly required for, apoptotic death. This is in agreement with studies in colon carcinoma cell lines induced to apoptosis by small chain fatty acids (butyrate) (Heerdt et al, 1997), as well as our

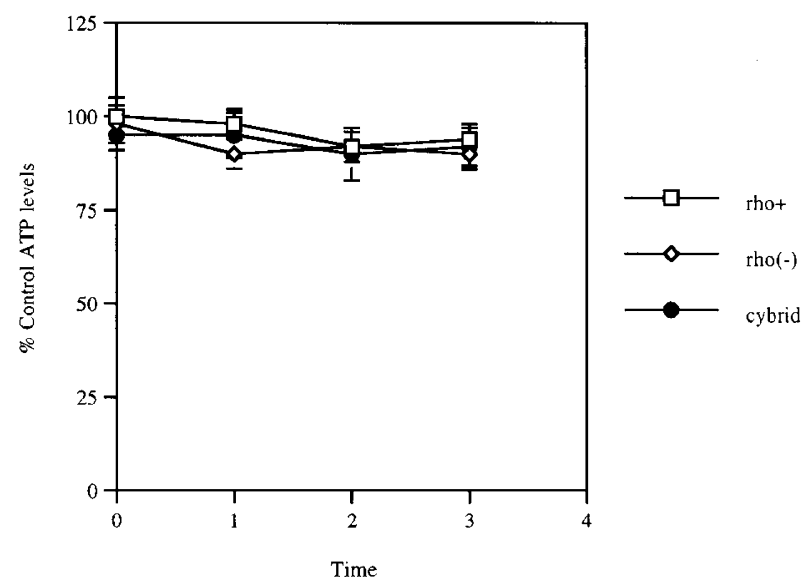

Figure 5 Effects of oligomycin on U937 ATP levels. To ensure the observed phenotype was not due to depletion of ATP levels in rho(-) cells, ATP levels were assessed after treatment with oligomycin $(12 \mu \mathrm{M})$, for up to $3 \mathrm{~h}$. ATP levels of the rho+ cells did not change during treatment with oligomycin. When expressed as a percentage of parental rho+ cells, the rho( -$)$ and cybrid cells did not differ with regard to ATP levels $(P>0.10$, Student $t$-test). This suggests that U937 cells, with and without mtDNA, are utilizing glycolysis for the vast majority of ATP synthesis, and that mitochondrial ATP synthesis is not responsible for the current observations previous studies in brain and breast cancer cells (Cavalli et al, 1997), and studies performed in immortal fibroblasts (Jacobson et al, 1993), noting that the cells continued to show apoptotic changes despite the absence of active mitochondria. As well, other evidence suggests mtDNAencoded molecules are related to the resistance to cisplatininduced apoptosis: Ara et al. (1994) found increases in mitochondrial cytochrome-c-oxidase in diverse resistant cancer cell lines when compared to sensitive parental cells, and speculated cisplatin resistant cells had mitochondrial alterations which were related to the resistant phenotype; Andrews and Albright (1992) have noted hyperpolarization of the mitochondrial membrane potential in cisplatin resistant ovarian carcinoma cells; this is particular intriguing, given the findings that the apoptotic cascade involves the loss of mitochondrial membrane potential as an early event (Marchetti et al, 1996a), followed by later apoptotic alterations such as generation of reactive oxygen species and DNA fragmentation (Deckwerth and Johnson, 1993). Indeed, Decaudin et al. (1997) have observed disruption of the mitochondrial membrane potential is an obligatory step of early apoptosis, although recent studies have also suggested mitochondrial involvement in apoptosis may be mitochondrial membrane potential independent (Yang et al, 1997; Kluck et al, 1997). Hence, in total, these data indicate a mitochondrial role in cisplatin-induced apoptotic death, with increases in sensitivity associated with depletion of mtDNA.

In contrast, other studies in colonic carcinoma, have found that increases in mitochondrial function are required for cells to undergo apoptosis (Heerdt et al, 1997), and steady-state mitochondrial mRNA levels are diminished in flat mucosa of patients susceptible for developing colon cancer (Heerdt et al, 1996). This may be related to tissue specificity, as well as the relative stage at which tumor cells are examined. Indeed, we have observed that in an ethylnitrosourea induced astrocytoma model, mitochondrial mass and $\Delta \Psi \mathrm{m}$ are decreased ontologically early, and gradually increase as cells progress from an immortal phenotype to a tumorigenic one (unpublished observations). However, mtDNA seems to increase early, and be maintained through the most malignant astrocytoma, the glioblastoma multiforme (Liang and Hays, 1996). Hence, the observed changes in mitochondria, mtDNA (and mRNA expression), and $\Delta \Psi \mathrm{m}$ may be dependent on the developmental stage of the neoplastic tissue evaluated. As well, the apoptotic stimuli in these aforementioned studies of colon carcinoma included differentiation agents, rather than cytotoxic agents as used in this report. Indeed, recent studies have shown the mitochondria to be involved in several pathways culminating in apoptosis, differing in the induction of MACH1/FLICE protease and inhibition by BCL2 (Susin et al, 1997). Of interest is that both our study, and the colon carcinoma studies by Heerdt (1996, 1997), mitochondria seem important in events leading up to apoptosis, but are not required for the apoptotic process per se. The mitochondria thus may be playing dual roles in the events leading up and modulating sensitivity to a cell's ability to undergo programmed cell death, in the context of specific stimuli or milieu, although the actual effector mechanism may be mitochondria independent. 
No changes were noted in the mRNA expression of MDR1, MRP, BCL2, BAX, ERCC1 or ERCC2 genes in the U937 rho+, rho(-), or cybrid cells. Changes in mRNA expression of these genes in human tumors resistant to cisplatin-induced apoptosis has been noted, with or without cross resistance to other agents (Dabholkar et al, 1992, 1994; Miyashita and Reed, 1993; Lim, 1996; Decaudin et al, 1997; Ara et al, 1994; Biedler, 1994; Chan et al, 1995; Goldstein, 1995; Nooter and Sonneveld, 1993; Rodriguez et al, 1993; Parekh and Simpkins, 1996; Chao, 1995). It has been unclear whether changes in the drug resistance genes MDR1 and MRP and the nucleotide excision repair genes ERCC1 and ERCC2 are mechanistically responsible for changes in cisplatin sensitivity in the studied tissues, or unrelated to the phenotype (Dabholkar et al, 1992, 1994; Biedler, 1994; Chan et al, 1995; Goldstein, 1995; Nooter and Sonneveld, 1993; Rodriguez et al, 1993; Parekh and Simpkins, 1996; Chao, 1995). Our data in U937 cells do not suggest changes in the mRNA expression of these genes play a direct role in sensitivity to cisplatin-induced apoptosis in U937 cells. As well, others have noted that overexpression of BCL2, or modification of the mRNA levels of BAX and BCL2 can change the relative sensitivity of cells to cisplatin-induced apoptosis (Hannun, 1997, and references therein). We did not observe changes in the levels of these apoptotic genes with changes in sensitivity to cisplatin-induced apoptosis. Hence, downstream events involved in the control of apoptosis from BCL2/BAX may be involved in the changes in sensitivity noted to cisplatininduced apoptosis. This has been hypothesized recently (Susin et al, 1997).

More recent studies have shown that the mitochondria can be effectively targeted in tumor cells (Ara et al, 1994; Chao, 1995; Oudard et al, 1995; Burger et al, 1995), and that the agents used have some degree of anti-tumor activity. Indeed, in vitro selectivity of some lipophillic cation compounds to the elevated mitochondrial membrane potentials in cancer cells (as compared to normal tissue counterparts) makes them particularly attractive for use as anti-neoplastic agents (Marchetti et al, 1996a; Oudard et al, 1995; Burger et al, 1995; Sun et al, 1996; Kerr et al, 1994). It could be hypothesized that treatment of malignant tissues with an anti-mitochondrial agent, to chemosensitize the tumor, followed by more 'standard' cytotoxic agents, may be an immediate approach to be investigated, either as initial or salvage therapy. Further studies in the circumvention of resistance to drug-induced apoptosis, by targeting mitochondria in the laboratory and clinical setting, will be interesting to determine the viability of such an approach in cancer therapy.

\section{Materials and Methods}

\section{Drugs}

Cis-diamminedichloroplatinum (cisplatin) was obtained from the manufacturer (Bristol-Myers Squibb Company, Princeton, NJ, USA) and prepared $<1 \mathrm{~h}$ before use. Ethidium bromide and acridine orange were purchased from Sigma (St. Louis, MO, USA) and used as $10 \mathrm{mg} /$ $\mathrm{ml}$ stock solutions in phosphate buffered saline (PBS), pH 7.4.

\section{Culture conditions}

The lymphoma cell line U937 (derived from the plural effusion of a patient with diffuse histiocytic lymphoma) was purchased from ATCC (Sundstrom and Nilsson, 1976). U937 cells were maintained in RPMI 1640 medium, supplemented with $10 \%$ fetal calf serum, 10,000 units of penicillin-streptomycin, $4.5 \mathrm{~g} / \mathrm{l}$ glucose, $50 \mu \mathrm{g} / \mathrm{ml}$ uridine and $1 \mathrm{mM}$ pyruvate. All culture medium and supplements were obtained from Life Technologies (Gaithersburg, MD, USA). mtDNA-less ('rho(-)') cells without mtDNA were established by incubating rho+ U937 cells with low dose $(30 \mathrm{ng} / \mathrm{ml}) \mathrm{EtBr}$ for at least 30 population doublings (King and Attardi, 1996). Since $\mathrm{EtBr}$ is an inhibitor of mtDNA replication (Wilkie et al, 1983), during cell growth the initial number of mtDNA molecules is decreased by a factor of two each time the cells divide. Hence, by treatment of cells for 30 doublings, $1 / 2^{30}$ or $<1 \%$ of the original number of mtDNA molecules should be present.

\section{Characterization of rho( - ) cells}

Auxotrophic dependence of $\mathrm{EtBr}$ treated cells to uridine is a signature of rho $(-)$ cells, and is a sensitive way to determine the respiratory status and thus the mtDNA content of cells (King and Attardi, 1996). Cells lacking mtDNA are unable to grow in the absence of pyrimidine and pyruvate. Cells were treated for at least 30 population doublings with $\mathrm{EtBr}$ and grown to confluence. Half the cells were transferred to medium lacking either uridine or pyruvate, but otherwise as described, with the other aliquot in complete medium including these supplements. The amount of cells present was assessed using the CellTiter 96 Aqueous Kit (Promega, Madison, WI, USA). The ethidium bromide/acridine orange assay for chromatin condensation was performed as per Schwarz et al. (1995). At least 400 cells were counted per experiment, which was replicated at least three times.

\section{Drug sensitivity studies}

U937 cells $\left(5 \times 10^{3}\right)$ were distributed into separate wells of a 96-well plate and treated with cisplatin for $1 \mathrm{~h}$; the medium was subsequently removed and cell survival was quantitated using the CellTiter 96 Aqueous Kit (Promega, Madison, WI, USA), following the manufacturer instructions. Data points represent the mean results of at least three different experiments. Significant differences were derived using a two-sided Student $t$-test.

\section{Cybrid studies}

Cybrids of the rho(-) cells were constructed as described (Cavalli et al, 1997), modified from Chomyn (1996). Platelets were isolated from normal human blood, resuspended in physiologic saline, and pelleted. $10^{6}$ U937 cells were pelleted, and resuspended in DMEM medium (Biofluids, Rockville, MD, USA) supplemented with $10 \%$ fetal calf serum (Life Technologies, Gaithersburg, MD, USA). The resuspended rho $(-)$ cells were then layered onto the platelet pellet, and the entire solution was recentrifuged at $180 \mathrm{~g}$ for $10 \mathrm{~min}$ at room temperature. After removal of the supernatant, $0.1 \mathrm{ml}$ of a $42 \%$ PEG solution (BDH Laboratory Supplies, Poole, England) was added, and the cell/platelet pellet carefully resuspended. The resuspended pellet was then added to $10 \mathrm{ml}$ of $\mathrm{rho}(-)$ medium (see above), and a 1:10 dilution was made. Cells were plated with progressively higher dilutions into 96 well plates, and incubated in a $37^{\circ}$ incubator $\left(95 \%\right.$ air $\left./ 5 \% \mathrm{CO}_{2}\right)$ for 3 days. The medium was removed, and uridine free medium added to the cells. Fourteen days later, cells were isolated, and transferred to $35 \mathrm{~mm}$ petri dishes with uridine- and pyruvate-free medium. Different clones obtained in this fashion were then tested for the presence of 
mtDNA by Southern hybridization, restriction pattern of the mtDNA donor and polymorphic nuclear identity of the rho+ cells.

\section{Nucleic acid isolation/hybridization}

Dot blots were performed as previously described (Liang et al, 1995), using $1 \mu \mathrm{g}$ of DNA. Densitometry was performed as noted (Liang, 1996a). Since bulk genomic DNA (nuclear and mitochondrial) was being used, it was assumed that equal loading of DNA samples would reflect the proportion of mtDNA present; hence, reported results are normalized to the $\beta$-actin control signal. DNA and mRNA isolation was as described (Liang, 1995). Probes were labeled using the Prime-aGene kit (Promega, Madison, WI, USA), and blots were constructed as described previously (Liang, 1994). The MDR1 cDNA probe was a generous gift from Dr. Susan Bates (NCl; Bethesda, MD, USA); MRP cDNA probe was obtained previously (Liang, 1996a); the BAX cDNA probe was a generous gift from Dr. Stanley Korsmeyer (Washington University; St. Louis, MO, USA); the BCL2 and $\beta$-actin cDNA probes were obtained from the ATCC (Rockville, MD, USA). Probes for ERCC1 and ERCC2 were derived previously (Liang et al, 1995). A mtDNA probe (corresponding to mtDNA positions $748-3318$ ) was constructed as noted (Liang et al, 1995). Reverse northern analysis was as described (Zhang et al, 1996). One $\mu \mathrm{g}$ of gene cDNAs was diluted in $200 \mu \mathrm{l}$ water, and applied to a Hybond $\mathrm{N}$ filter, using a slot blot manifold (Stratagene, LaJolla, CA, USA). Total RNA (10 $\mu \mathrm{g}$ ) was isolated from cells according to the manufacturer instructions (Invitrogen, Carlsbad, CA, USA) and diluted in $50 \mu$ ldistilled water. Subsequently, RNA was reverse transcribed using the Riboclone kit (Promega, Madison, WI, USA) according to the manufacturer instructions, in the presence of $\left[\alpha^{-32} \mathrm{P}\right] \mathrm{dCTP}(5 \mu \mathrm{l}, 3000 \mathrm{mCi} / \mathrm{mmol})$. Labeled cDNA was treated with RNase A $\left(1 \mathrm{mg} / \mathrm{ml} ; 37^{\circ} \times 60 \mathrm{~min}\right)$. Probes were added to each filter in hybridization solution $(1 \mathrm{M} \mathrm{NaCl}$, $1 \%$ SDS, $10 \%$ Dextran sulfate, $50 \mu \mathrm{g} / \mathrm{ml}$ sheared salmon sperm DNA), exposed overnight at $60^{\circ}$, and washed in $2 \times \operatorname{SSC} / 1 \% \operatorname{SDS}\left(60^{\circ}\right)$ for 30-60 min. Filters were exposed to film between $2-3$ days at $-80^{\circ}$.

\section{Nuclear and mitochondrial identity}

Nuclear and mitochondrial identity were established by using polymorphic markers and differences in restriction pattern from the tumor cell mtDNA and the platelet donor. For nuclear identity, the marker D10S591 (Research Genetics, Huntsville, AL, USA) was used to amplify DNA from the rho+, rho(-), and cybrid populations, as previously described (Kimmelman et al, 1996). Mitochondrial identity was determined by amplifying a fragment of mtDNA from positions $1546\left(5^{\prime}\right)$ to $705\left(3^{\prime}\right)$, as described (Liang and Hays, 1996), with subsequent digestion with Taql. Donor mtDNA has a polymorphism in this non-coding region of mtDNA, with a guanine replacing a cytosine at position 44, creating a Taql site.

\section{Determination of ATP levels}

ATP levels were determined by using Sigma Kit 366 (Sigma, St. Louis MO, USA) according to the manufacturer's instructions. Experiments were performed at least in triplicate.

\section{Acknowledgements}

$\mathrm{BCL}$ is the recipient of an American Society of Clinical Oncology Career Development Award (PN9511-029), and is supported by the American Institute for Cancer Research (AICR 96B009), the Cancer League of Colorado (PN9602-083) and the National Cancer Institute (CA73916). We thank Drs. Susan Bates and Stanley Korsmeyer for probes and Drs.
Karen Newell, Paul Bunn and Roderic Smith for helpful comments and discussions.

\section{References}

Andrews PA and Albright KD (1992) Mitochondrial defects in cis-diamminedichloroplatinum (II)-resistant human ovarian carcinoma cells. Cancer Res. 52: 18951901

Ara G, Kusumoro T, Korbut TT, Cullere-Luengo F and Teicher BA (1994) cisDiamminedichloroplatinum (II) resistant human tumor cell lines are collaterally sensitive to $\mathrm{PtCl}_{4}(\mathrm{Rh}-123)_{2}$ : Evidence for mitochondrial involvement. Cancer Res. 54: 1497-1502

Biedler JL (1994) Drug resistance: Genotype versus phenotype-thirty-second G.H.A. Clowes Memorial Award Lecture. Cancer Res. 54: 666-678

Burger AM, Kaur G, Alley MC, Supko JG, Malspeis L and Grever MR (1995) Tyrphostin AG17, [(3,5-Di-tert-butyl-4-hydroxybenzylidene)-malononitrile], inhibits cell growth by disrupting mitochondria. Cancer Res. 55: 2794-2799

Castedo M, Macho A, Zamzani N, Hirsch T, Marchetti P, Uriel J and Kroemer G (1995) Mitochondrial perturbations define lymphocytes undergoing apoptotic depletion in vivo. Eur. J. Immunol. 25: 3277-3284

Cavalli L, Varella-Garcia M and Liang BC (1997) Changes in tumorgenic phenotype acheived by depletion of mitochondrial DNA. Cell Growth and Differentiation 8: $1189-1198$

Chan HS, DeBoer G, Haddad G, Gallie BL and Ling V (1995) Multidrug resistance in pediatric malignacies. Hematology - Oncology Clinics of North America 9: 275318

Chao CC (1995) Lack of elevated drug efflux in adriamycin-resistant immumoblastic B lymphoma cells with mdr1 overexpression. FEBS Letters 373: 285-290

Chomyn A (1996) Platelet mediated transformation of human mitochondrial DNAless cells. Methods in Enzymology: Mitochondrial Biogenesis and Genetics 246: $334-339$

Cossarizza A, Franceschi C, Monti D, Salvioli S, Bellesia E, Rivabene R, Biondo L, Rainaldi G, Tinari A and Malorni W (1995) Protective effect of $\mathrm{N}$-acetylcysteine in tumor necrosis factor- $\alpha$-induced apoptosis in U937 cells: the role of mitochondria. Exp. Cell Res. 220: 232-240

DabholkarM, Bostick-Bruton Rand ReedE (1992)ERCC1 and ERCC2 expression in fresh human tumor tissues. Journal of the National Cancer Institute 84: 15121517

Dabholkar M, Vionnet J, Bostick-Bruton F, Yu JJ and Reed E (1994) Messenger RNA levels of XPAC and ERCC1 in ovarian cancer tissue correlate to response to platinum based chemotherapy. Journal of Clinical Investigation 94: 703-708

Decaudin D, Geley S, Hirsch T, Castedo M, Marchetti P and Macho A (1997)Bcl-2 and $\mathrm{Bcl}-\mathrm{X}$ antagonize the mitochondrial dysfunction preceding nuclear apoptosis induced by chemotherapeutic agents. Cancer Res 57: 62-67

Deckwerth TL and Johnson EM (1993) Temporal analysis of events associated with programmed cell death (apoptosis) of sympathetic neurons deprived of nerve growth factor. J. Cell Biol. 123: 1207-1222

Eguchi Y, Shimizu S and Tsujimoto Y (1997) Intracelluar ATP levels determine Cell Death Fate by Apoptosis or Necrosis. Cancer Res 57: 1835-1840

Friesen C, Herr I, Krammer PH and Debatin K-M (1996) Involevement of the CD95 (APO-1/Fas) receptor/ligand system in drug-induced apoptosis in leukemia cells. Nature Medicine 2: 574-578

Goldstein LJ (1995) Clinical reversal of drug resistance. Current Problems in Cancer 19: $65-124$

Hannun YA (1997) Apoptosis and the Dilemma of Cancer Chemotherapy. Blood 89: $1845-1853$

HeerdtBG, Houston MA and Augenlicht LH (1997) Short-chain fatty acid-initiated cell cycle arrest and apoptosis of colonic epithelial cells is linked to mitochondrial function. Cell Growth \& Differentiation 8: $523-532$

HeerdtBG, Houston MA, Rediske JJ and Augenlicht LH (1996) Steady-state levels of Mitochondrial Messenger RNA Species characterize a Predominant Pathway culminating in apotosis and shedding of HT29 Human Colon Carcinoma Cells. Cell Growth and Differentiation 7: 101-106

Jacobson MD, Burne JF, King MP, Miyashita T, Reed JC and Raff MC (1993) Bcl-2 blocks apoptosis in cells lacking mitochondria. Nature 361: 365-369

Jacobson MD, Burne JF and Raff MC (1994) Programmed cell death and bcl-2 protection in the absence of a nucleus. EMBO J. 13: 1899-1910 
Kerr JFR, Winterford CM and Harmon BV (1994) Apoptosis: its significance in cancer and cancer therapy. Cancer 73: 2013-2016

Kimmelman A, Ross D and Liang BC (1996) Loss of heterozygosity of chromosome $10 p$ in human gliomas. Genomics 34: $250-254$

King MP and Attardi G (1996) Isolation of human cell lines lacking mitochondrial DNA Methods in Enzymology: Mitochondrial Biogenesis and Genetics 264:304 - 313. Academic Press, Inc

Kluck RM, Bossy-Wetzel E, Green DR and Newmeyer DD (1997) The release of cytochrome c from mitochondria: a primary site for bcl-2 regulation of apoptosis. Science 275: $1132-1136$

Kroemer G, Petit PX, Zamzani N, Vayssiere JL and Mignotte B (1995) The biochemistry of apoptosis. FASEB J. 9: 1277-1287

Landowski TH, Gleason-Guzman MC and Dalton WS (1997) Selection for Drug Resistance results in Resistance to Fas-mediated Apoptosis. Blood 89: 18541861

Liang BC and Hays L (1996) Mitochondrial DNA copy number alterations in human gliomas. Cancer Letters 105: 167-173

Liang BC, Ross DA, Greenberg HS, Metzler PS and Trent JM (1994) Evidence of allelic imbalance of chromosome 6 in glial neoplasms. Neurology 17: 91-96

Liang BC, Ross DA and Reed E (1995) Genomic DNA copy number changes of DNA repair genes ERCC1 and ERCC2 in human gliomas. J. Neuroonc. 26: 17-23

Liang BC (1995) Direct isolation of variably amplified cDNAs from human tumor cell lines. Int. J. Onc. 7: 611-615

Liang BC (1996a) Effects of hypoxia on drug resistance phenotype and genotype in human glioma cell lines. J. Neuroonc. 29: 149-155

Lim LC (1996) Molecular genetics of B-cell lymphomas: a review. Annals of the Academy of Medicine, Singapore 25: 37-41

Marchetti P, Castedo M, Susin SA, Zamzani N, Hirsch T, Macho A, Haeffner A, Hirsch F, Geuskens M and Kroemer G (1996a) Mitochondrial permeability transition is a central coordinating event of apoptosis. J. Exp. Med. 184: 1155-1160

Marchetti P, Susin SA, Decaudin D, Gamen S, Castedo M, Hirsch T, Zamzani N, Naval J, Senik A and Kroemer G (1996b) Apoptosis associated derangement of mitochondrial function in cells lacking mitochondrial DNA. Cancer Res. 56: 2033-2038

Miyashita T and Reed JC. (1993) BCL-2 oncoprotein blocks chemotherapy-induced apoptosis in a human leukemia cell line. Blood 81: 151-157

Nooter K and Sonneveld P (1993) Multidrug resistance (MDR) genes in haematological malignancies. Cytotechnology 12: 213-230

Oudard S, Poirson F, Miccoli L, Bourgeois Y, Vaxxault A and Poisson M (1995) Mitochondria-bound hexokinase as target for therapy of malignant gliomas. Int. J. of Canc. 62: 1-7
Parekh Hand Simpkins H (1996) Cross-resistance and collateral sensitivity to natural product drugs in cisplatin-sensitive and -resistant rat lymphoma and human ovarian carcinoma cells. Cancer Chemotherapy and Pharmacology 37: 457462

Petit PX, LeCouer H, Zorn E, Dauget C, Mignotte B and Gougeon ML (1995) Alterations of mitochondrial structure and function are early events of dexamethasone-induced thymocyte apoptosis. J. Cell Biol. 130: 156-167

Richter C, Schweizer M, Cossarizza A and Franceschi C (1996) Control of apoptosis by the cellular ATP level. FEBS Letters 378: 107-110

Rodriguez C, Commes T, Robert J and Rossi JF (1993) Expression of P-gylcoprotein and anionic glutathione S-transferase genes in non-Hodgkin's lymphoma. Leukemia Res 17: 149-156

Schulze-Osthoff K, Walczac H, Droge W and Krammer D (1994) Cell nucleus and DNA fragmentation are not required for apoptosis. J. Cell Biol. 127: 15-20

Schwartz LM, Milligan CE, Bielke W and Robinson SJ (1995) Cloning Cell Death Genes. Cell Death Chapter 7: I-V. Academic Press, Inc

Sun X, Wong JR, Song K and Chen LB (1996) Anticarcinoma activity of a novel drug, 3-ethyl-3'-methyl-thiatelluracarbocyanine iodine (Te), a tellurium-containing cyanine targeted at mitochondria. Clin. Canc. Res. 2: 1335-1340

Sundstrom C and Nilsson K (1976) Establishment and characterization of a human histiocytic lymphoma cell line (U937). Int. J. Canc. 17: 565-577

Susin SA, Zamzami N, Castedo M, Daugas E, Wang H-G, Geley S, Fassy F, Reed JC and Kroemer G (1997) The Central Executioner of Apoptosis: Multiple Connections between Protease Activation and Mitochondria in Fas/APO-1/ CD95- and Ceramide-induced Apoptosis. Journal Experimental Medicine 186: 25-37

Warburg O, Wind F and Negelein E (1926) Uber den Stoffwechsel von Tumoren in Korper. Klin Woch 5: 829-832

Wilkie D, Evans IH, Egilsson V, Diala ES and Collier D (1983) Mitochondria, cell surface, and carcinogenesis. International Review of Cytology. Supplement 15, 157-189:, Academic Press, Inc

Yang J, Liu X, Bhalla K, Kim CN, Ibrado AM, Cai J, Peng T-I, Jones DP and Wang X (1997) Prevention of apoptosis by bcl-2: release of cytochrome $c$ from mitochondria blocked. Science 275: 1129-1132

Zamzani N, Marchetti P, Castedo M, Zanin C, Vayssiere J-L, Petit PX and Kroemer G (1995) Reduction in mitochondrial potential constitutes an early irreversible step of programmed lymphocyte death in vivo. J. Exp. Med. 181: 1661-1672

Zhang H, Zhang R and Liang P (1996) Differential screening of gene expression difference enriched by differential display. Nucleic Acids Res. 24: 2454-2455 